\title{
Sustained Transfusion Independence in Chronic Bone Marrow BM Failure under Long-Term Self-Administration of Moringa Oleifera
}

Massimiliano Palombi, Pasquale Niscola ${ }^{*}$, Malgorzata Monika Trawinska, Elisabetta Abruzzese, Andrea Tendas, Laura Scaramucci, Stefano Fratoni, Marco Giovannini, Francesco Bondanini ${ }^{\circ}$, Roberto Palumbo ${ }^{\wedge}$, Paolo de Fabritiis

Hematology Unit, Pathology Department, Laboratory Medicine Department ${ }^{\circ}$, Nephrology Unit^, S. Eugenio Hospital, Rome Italy

DOI: $10.36348 /$ sjm.2020.v05i01.010

| Received: 20.11.2019 | Accepted: 27.12.2019 | Published: 29.01.2020

*Corresponding author: Pasquale Niscola

\section{Abstract}

A case of sustained transfusion independence in a patient affected by chronic bone marrow failure by gelatinous transformation under long term self-administration of moringa oleifera is reported.

Keywords: anemia, bone marrow failure, gelatinous transformation, moringa oleifera, transfusion independence.

Copyright @ 2020: This is an open-access article distributed under the terms of the Creative Commons Attribution license which permits unrestricted use, distribution, and reproduction in any medium for non-commercial use (NonCommercial, or CC-BY-NC) provided the original author and source are credited.

\section{INTRODUCTION}

Bone marrow (BM) failure by gelatinous transformation (GT) is a rare hematological disorder which is characterized by fat cell atrophy, focal loss of hematopoietic stem cells, and deposition of extracellular gelatinous substances (mucopolysaccharides rich in hyaluronic acid), resulting in the alteration of the BM microenvironment and the stroma as well as the disruption of interactions between BM cells and cell signaling molecules [1]. Therefore, hematopoiesis is hampered and the diseaserelated peripheral cytopenias became prominent clinical features. The pathogenesis of GT of BM is unknown, having this degenerative condition been reported in association with chronic debilitating diseases, such as anorexia nervosa, malnutrition, human immunodeficiency virus infection as well as after cytotoxic treatments; in addition, GBMT has been described in patients with myeloid malignancies [1]. Our group reported several years ago a case of idiopathic GT of BM [2] observed in a patient who had an unusual clinical course and a long-term survival [3]. Herein, we report an updated of the patient's outcome in the light of the long lasting transfusion independence (TI) observed by us, as an incidental finding, from about 25 months under the self-administration of a complementary measure, such as moringa oleifera (MO).

\section{CASE REPORT}

A 64-year-old Caribbean woman, who had been living in Rome for more than 30 years, was diagnosed as having idiopathic GT of BM in December
2005 [1], having us ruled out all known causes underlying this degenerative BM disorder; in particular, her nutritional status was excellent and she denied alcohol, drugs, or tobacco use. Moreover, neoplastic and autoimmune disorders as well as all common viral infections, such those portrayed by HIV, cytomegalovirus, Epstein-Barr virus, parvovirus B19, and hepatitis $\mathrm{B}$ and $\mathrm{C}$ viruses, were ruled out by appropriate diagnostic examinations. The BM aspirate performed at admission resulted in a hypocellular marrow without blasts and dysplasia. The BM trephine biopsy was taken and the histological examination, in the absence of blasts and fibrosis, revealed a GT. The patient did not respond to any potentially diseasemodifying treatment, including erythropoietin, prednisone, and cyclosporine [1]. Therefore, she was managed with supportive measures, primarily red blood cells (RBC) transfusions. In addition, iron chelation therapy was given as requested but was poorly tolerated and frequently interrupted until its suspension. However, although the patient remained transfusion dependent with a variable need for packed red blood cell (PRBC) units over the years (Table 1), her clinical course was relatively uncomplicated [3]. Unexpectedly, from the first few months of 2014, we observed progressively continuous improvements in hemoglobin values and a parallel reduced need for PRBC (last transfusion: 5 December 2015) until the complete transfusion independence that lasts from December 2005 until today (December 2019). Therefore, the patient's BM was about annually re-evaluated, being the pathological findings substantially compatible with the persistence of GT of BM. When we asked about any changes in her eating habits or about any medications 
administered on her own initiative, the patient reported that, from about the end of 2013, she was taking (MO), a phytotherapeutic complex, as a dietary supplement in an attempt to ameliorate the fatigue and improve her functional status. Moreover, believing the patient such natural substance as a harmless dietary supplement and not a drug, she had never believed necessary to inform us about the self-administration of this herbal complex. To date, over fourteen years later the primary diagnosis of GT, the patient is well and, inexplicably to the best of our effort to understand her hematological improvement, transfusion free from 4 years.

\section{DISCUSSION AND CONCLUSIONS}

To the best of our knowledge, no such case of TI for so long time has never been reported in patients with GT of BM after so many years of transfusion dependency not responding to any conventional treatment. In the absence of any plausible explanation, we may consider the sustained TI as due to a spontaneous improvement of her GT-related BM failure or to some, although not known and not explained, therapeutic effect provided by this phytoterapic agent. MO is a highly valued plant, provided of high nutritional value. It contains minerals, protein, vitamins, beta-carotene, amino acids and various phenolics as well as a combination of heterogeneous as well antioxidant and detoxifying substances [4]. Different pharmacological properties of MO has been reported $[4,5]$, for which this vegetable complex is distributed in many tropic and subtropics countries as therapeutic agent for a wide and impressive range of medical indications, including cardiac and circulatory diseases, diabetes, hypercholesterolemia, inflammations, fever, hypertension, liver disorders and so on [4]. Interestingly, from an oncological point of view, this multipurpose plant is thought to have chemopreventive potentials $[6,7]$ as well as prominent cytotoxicity $[8,9]$, inducing apoptosis as well as inhibiting the growth of human cancer cell lines in vitro models [8-10]. Given that GT of BM is a degenerative disorders which may develop in different pathological conditions, a basic bioregulatory processes may be likely involved in its pathogenesis. In this view, targeting some molecular pathogenetic mechanisms as well as inhibiting the angiogenesis and the production of inflammatory substances, such free radicals, MO could have exerted beneficial effects in our patient acting as an antioxidant, contrasting tissue injury, stimulating regeneration and, ultimately, improve her BM function. Obviously, MO as other natural compounds cannot be alternative to established therapies and it certainly cannot be recommended as a therapeutic measure in this setting. Indeed, our report should be considered purely anecdotal and devoid of any demonstration about possible biological mechanisms involved in potentially MO-induced effects. However, our observation may represent a suggestion in order to perform biological studies in vitro, as performed in the setting of various solid tumors, also in different hematological conditions dominate by $\mathrm{BM}$ failure and transfusion dependent anemia by using this plant complex or its specific constituents. Thereby, eventually promising findings, as reported in patients affected by pancreas carcinoma [10], may be translated in future clinical application of this natural compound as complementary measure in combination to established conventional or novel agents.

The authors have no conflict of interest to declare.

\section{REFERENCES}

1. Dewi, A., \& Hadri, M. (2017). Financial distress prediction in Indonesia companies: finding an alternative model. Russian Journal of Agricultural and Socio-Economic Sciences, 61(1).

2. Niscola, P., Maurillo, L., Palombi, M., Fratoni, S., Perrotti, A. P., Piccioni, D., ... \& De Fabritiis, P. (2007). Gelatinous degeneration of the bone marrow: two case reports showing different hematological features and clinical outcomes. Acta haematologica, 118(3), 165-166.

3. Niscola, P., Palombi, M., Fratoni, S., Trawinska, M. M., Scaramucci, L., Tendas, A., ... \& de Fabritiis, P. (2012). Long-term survival of a patient with bone marrow gelatinous degeneration of idiopathic origin. The Korean journal of hematology, 47(4), 309-310.

4. Leone, A., Spada, A., Battezzati, A., Schiraldi, A., Aristil, J., \& Bertoli, S. (2015). Cultivation, genetic, ethnopharmacology, phytochemistry and pharmacology of Moringa oleifera leaves: an overview. International journal of molecular sciences, 16(6), 12791-12835.

5. Araújo, L. C. C., Aguiar, J. S., Napoleão, T. H., Mota, F. V. B., Barros, A. L. S., Moura, M. C., ... \& Paiva, P. M. G. (2013). Evaluation of cytotoxic and anti-inflammatory activities of extracts and lectins from Moringa oleifera seeds. PLoS One, 8(12), e81973.

6. Michl, C., Vivarelli, F., Weigl, J., De Nicola, G. R., Canistro, D., Paolini, M., ... \& Rascle, A. (2016). The chemopreventive phytochemical moringin isolated from Moringa oleifera seeds inhibits JAK/STAT signaling. PloS one, 11(6), e0157430.

7. Akanni, E. O., Adedeji, A. L., Adedosu, O. T., Olaniran, O. I., \& Oloke, J. K. (2014). Chemopreventive and anti-leukemic effects of ethanol extracts of Moringa oleifera leaves on wistar rats bearing benzene induced leukemia. Current pharmaceutical biotechnology, 15(6), 563-568.

8. Sreelatha, S., Jeyachitra, A., \& Padma, P. R. (2011). Antiproliferation and induction of apoptosis by Moringa oleifera leaf extract on human cancer cells. Food and Chemical Toxicology, 49(6), 1270-1275.

9. Madi, N., Dany, M., Abdoun, S., \& Usta, J. (2016). Moringa oleifera's nutritious aqueous leaf extract has anticancerous effects by compromising 
mitochondrial viability in an ROS-dependent manner. Journal of the American College of Nutrition, 35(7), 604-613.

10. Berkovich, L., Earon, G., Ron, I., Rimmon, A., Vexler, A., \& Lev-Ari, S. (2013). Moringa Oleifera aqueous leaf extract down-regulates nuclear factorkappaB and increases cytotoxic effect of chemotherapy in pancreatic cancer cells. BMC complementary and alternative medicine, 13(1), 212. 